Data for:

\title{
Chronically-implanted Neuropixels probes enable high yield recordings in freely moving mice: dataset
}

Juavinett, A. L., Bekheet, G., Churchland, A. K. (August 2019)

*Correspondence: churchland@cshl.edu

Dateset DOI: $\quad$ https://dx.doi.org/10.14224/1.38304

Dataset Download location: http://labshare.cshl.edu/shares/library/repository/38304/ 